\title{
Laparoscopic splenectomy using bipolar vessel sealing system
}
Aws Kh. Jassim*
CABS
Fareed A. Turkey*
Ahmed A. Ibraheem*
CABS
MBChB

Abstract

Fac Med Baghdad 2015; Vol.57, No.1 Received: Dec, 2014 Accepted: Jan., 2015

Background: Newly developed vessels sealing device built upon bipolar diathermy technology had a great impact on facilitating advances laparoscopic surgery. Laparoscopic splenectomy is well established procedure but in this study the procedure is totally based on bipolar vessel sealing system in devascularization of the spleen.

Objective: To evaluate the safety of laparoscopic splenectomy with vessels sealing device and its outcome.

Patient and method: Prospective study conducted in Baghdad Teaching Hospital and Dijlah private hospital from October 2009 to October 2013. Thirty patients with idiopathic thrombocytopenic purpura(ITP) were included and had laparoscopic splenectomy. The adapted procedure was stapleless laproscopic splenectomy, without clips using vessels sealing device only.

Result: A total of 30 patients were recruited. The mean of their ages was 25.2 years. Eleven of them were males and 19 were females. The mean operative time was 84.3 min. The mean estimated blood loss was 105 $\mathrm{ml}$. Twenty seven spleens were extracted through small Pfannenstiel incision and 3 spleens were retrieved by retrieval bag. No conversion had occurred; the mean hospital stay was 2.3 days. Neither bleeding nor any other serious complication related to this technique were observed, only one patient complicated by collection which was treated by aspiration under ultrasound guide. No mortalities were recorded.

Conclusion: Laparoscopic splenectomy of normal size and mildly enlarged spleen with use of vessels sealing device without staple or clips is safe and effective.

Key words: spleenectomy, laparoscopic, vessel sealing systems.

\section{Introduction:}

The first splenectomy done by Zacarello in 1549 and O,Brien in 1816 in Europe and north America respectively(1). By 1877 only 50 splenectomies had been performed, with mortality rate more than $70 \%$. Yet by 1900 , large series of splenectomies were reported with an operative mortality rate dropped to less than $40 \%$, and in 1920 report of Myo clinic experience with splenectomy noted an $11 \%$ mortality rate(2).

The earliest reports of laparoscopic splenectomy were published in period between 1991 and 1992 by independently working four groups, Delaitre in Paris and Carollin in los Angeles, Cushieri in U.K and Poulin etal in Canada $(3,4)$. Since that time, operative technique for laparoscopic splenectomy was developed and put the limits for minimaly invasive surgery under test until now where the technique of the operation is much simplified $(5,6)$.In the other hand ,development in video laproscopy, innovation videography with introduction of high definition cameras resulting in higher resolution image had a great impact on performance of advanced laparoscopic procedures (7). Haemostasis is a major concern of laparoscopic

*Dept. of Surgery, Baghdad Teaching Hospital, Corresponding Auther: Fareed A. Turkey.

e.mial: fadansarr26@gmial.com surgeons they use ligature, titanium clips, electrical diathermy and laparoscopic stapling device (8). Electrical diathermy can be monopolar or bipolar.

The common monopolar instruments are: scissor, hook and spatula. However injury were common, like insulation failure ,direct coupling, and capacitative coupling around active electrode and may cause serious burn and tissue damage to the patients undergoing laproscopic procedure(9). The factors that increase these types of injury include using of long instrument, thinner insulation, higher voltage and narrow trocars (10). These limitations were overcome by use of bipolar electrocautary(11).

Bipolar technology employs passing the current in an active electrode back through a return electrode, both in a single electrosurgical instrument with two small poles rather than passing it through the patient to grounding pad as in monopolar cautery. The alternating current will be distributed through the target tissue only (12), so it causes less complication than the monopolar cautery. Lower voltages are needed to achieve the same tissue effect in bipolar electrosurgery as those in monopolar because the poles are closer to each other, thus less potential damage to surrounding tissue and less risk of capacitive 
coupling(10). Classic bipolar instrument is the kleppinger bipolar forceps used most commonly for laparoscopic tubal sterilization and hemostasis of vascular pedicles. Bipolar forceps allow for firm grasping and reliable coagulation of vessels less than $3 \mathrm{~mm}$ in size. Newly developed vessels sealing device built upon bipolar diathermy technology had a great impact on facilitating advances laparoscopic surgery. Laparoscopic splenectomy is well established procedure but in this study the procedure is totally basedon bipolar vessel sealing system in devascularization of the spleen, this new Vessel sealing device is bipolar electrosurgical device that delivers high current low voltage along with pressure from the jaw to the tissue. Vessels sealing device can seal vessels up to $7 \mathrm{~mm}$ in size. Of note, this differs from the high voltage, low current energy used in standard monopolar cautery. In bipolar technology the system monitors the energy expended while denaturing the collagen and elastin within the vessels wall. During the cooling phase of cycle, cross linking re-occurs creating new seal. At the end of the cycle the device generator produces a bleep sound that denotes complete sealing of the vessel and permit division. This instrument is available in 5and $10 \mathrm{~mm}$ size (13).

\section{Patients and method:}

This is a prospective study conducted in Baghdad Teaching Hospital and Dijlah private hospital during the period from October 2009 to October 2013 including 30 patients with idiopathic thrombocytopenic purpura(ITP) who were primarily dignosed and treated by hematologist and then referred for splenectomy. Patients who have indication for splenectomy were either chronic steroid dependent, or taking high dose of steroid to reach normal platelet count. In our department, evaluation of the patients by history and physical examenation and investigation i.e (complete blood count, renal function test, coagulation profile (PT, PTT,INR) and bleeding time, random blood sugar, respiratory function test, and abdominal ultrasound to assess the size of spleen and any other pathology\}. Those patients with midline scar of previous operation were excluded from this study. Those patients with enlarged spleen were operated on laparoscopically and if any need for clipping of the vessels occurred during surgery they were excluded from the study as well. All of the patients were vaccinated for pneumococcal, meningococcal, and H.influenza. The vaccines were given to the patients two weeks prior to surgery. Platelets preparation was either in the form of ordinary used platelets or fresh donor platelets if the platelet count was lower than 50000 per ml given after devasculrization of the spleen. Prophylactic i.v antibiotic was given within one hour before operation. In the theatre, the patient is positioned in right lateral decubitus; the position is maintained by lateral support. This position made the spleen hung from its posterior attachment. Drapping of the patient and then the abdominal cavity is insufilated by $\mathrm{CO} 2$ gas to $12 \mathrm{~mm} \mathrm{Hg}$ at a point which is three fingerbridths below costal margin in the midclavicular line through which the optical port is inserted. After that, a $2 \mathrm{nd} 10 \mathrm{~mm}$ working port is introduced subcostally in the anterior axillary line and a 3rd working port below xyphoid sternum and slightly to the left which is $5 \mathrm{~mm}$.

Firstly we search for any spleniculi in the hilum of the spleen or in the greater omentum or the other parts of abdomen and if there, we excise it first. Then we start using a $10 \mathrm{~mm}$ vessel sealing system (ligasure or maxium) for division of lowest ligamental attachment of the spleen at the lower pole with leaving some stump at splenic side for assisting handling the spleen during procedure, the plane of dissection and division kept with the splenic capsule and hilum to make vessel sealing instrument facing only terminal branches and tributaries of splenic vessels and not major splenic vessels. By keeping this role we also avoid gastric wall during division of short gastric vessels. During the procedure and after each bite by the vessel sealing instrument, we noticed segmental blue disclouration of the spleen and after completing division proximal to splenic hilum we instructed the anaesthetist to give platelets. After division of the last ligamental attachment at the upper pole the spleen will be completely free, we grasp the stump that left in the lowe pole and guide it to the pelvis and small Pfannenstiel incision $(6 \mathrm{~cm})$ done for extraction of the spleen out of abdominal cavity. If retrieval bag was available the spleen retrieved from the $10 \mathrm{~mm}$ port. Tube drain was inserted in the left subphrenic space.

Post operatively patients were followed up during their hospital stay. Early mobilization and oral fluids were started 6-8 hours after surgery. 1st postoperative day platelet count was done and repeated weekly thereafter. Patients were discharged home after 2-3 days. Drain was removed after 2-3 days and the stitches at day ten.

Information regarding the demographic and clinical features of the patients and the operative findings and postoperative results and complication were arranged in tables and evaluated.

\section{Results:}

A total of 30 patients under went laparoscopic splenectomy in Baghdad Teaching Hospital and Dijlah private hospital for a period from October 2009 to October 2013 by a single team of surgeons. Their age ranged from 10 years to 45 years with mean of (25.2years). There were 19 females and 11 males. Three patients had concomitant laparoscopic cholecystectomy. All patients in this study were suffering from ITP .Craniocaudal length ranged from $10 \mathrm{~cm}$ to $17 \mathrm{~cm}$ with mean of $(13.3 \mathrm{~cm})$. As shown in table (1) 
Table (1) Demographic and clinical features of the study patients

\begin{tabular}{lll}
\hline Number of patients & 30 & \\
\hline \multirow{2}{*}{ Gender } & Male 11 & $36.6 \%$ \\
\cline { 2 - 3 } & Female 19 & $\mathbf{6 3 . 3 \%}$ \\
\hline Mean age & 25.2 years & Range(10-45 years) \\
\hline Mean splenic size & $13.3 \mathrm{~cm}$ & Range(10-17cm) \\
\hline Indication & ITP & $100 \%$ \\
\hline $\begin{array}{l}\text { Mean platelet count pre } \\
\text { operatively }\end{array}$ & $46,000 / \mathrm{ML}$ & Range(15,000-90,000/ML) \\
\hline
\end{tabular}

The average operation time was $84.3 \mathrm{~min}$. (Range $60-120 \mathrm{ml}$ ). Mean estimated blood loss was $105 \mathrm{ml}$ (range60-150ml). Twenty seven spleens were extracted by small Pfannenstiel incision and 3 spleens were retrieved by retrieval bag through site of $10 \mathrm{~mm}$ port. Five patients had a spleneculi and no patient required a conversion to open procedure as shown in table (2)

\section{Table (2) Operative result}

\begin{tabular}{lll}
\hline Mean operation time & $84.3 \mathrm{~min}$. & Range 60-120 min.) \\
\hline Spleniculi & 5 patients & $16.6 \%$ \\
\hline Mean estimated blood loss & $105 \mathrm{ml}$ & Range $(60-150 \mathrm{ml})$ \\
\hline Conversion & 0 & $0 \%$ \\
\hline
\end{tabular}

The immediate post-operative period was uneventful, however, complication observed in 7 patients $(23.3 \%)$ as shown in table (3). Four patients complicated with subcutenous ecchymosis at site of Pfannenstiel incision and mainly observed in patients with low platelet count pre operatively all of the four patients treated conservatively, one patient complicated by left sub phrenic collection which treated by aspiration under ultrasound guide, and one patient complain from abdominal pain in day 10 post operatively and diagnosed as splenic portal vein thrombosis by ultrasound with doplex scan and treated by enoxaparin and last patient complicated by high elevation of platelet count in post-operative day 2 and also treated by enoxaparin.

\section{Table (3) Post-operative result}

\begin{tabular}{llll}
\hline Mean hospital stay & 2.3 days & Range 2-3 days & \\
\hline $\begin{array}{l}\text { Mean platelet count } \\
\text { post operatively }\end{array}$ & $\begin{array}{l}248,000 / \\
\text { ML }\end{array}$ & Range(250,000-400,000/ML) \\
\hline & & Echymosis & 4 patients \\
\cline { 3 - 4 } Complication & $\begin{array}{l}\text { 7 patients } \\
(23.3 \%)\end{array}$ & $\begin{array}{lll}\text { Subphrenic } \\
\text { collection }\end{array}$ & 1 patient \\
\cline { 2 - 3 } & & $\begin{array}{l}\text { Spleno-portal } \\
\text { vein thrombosis }\end{array}$ & 1 patient \\
\cline { 2 - 4 } & & thrombocytosis & 1 patient \\
\hline
\end{tabular}

\section{Discussion:}

Since first introduction by delaitre in 1991.Laparoscopic splenectomy had gained popularity worldwide and in many instances substituted open surgery as the standard procedure of choice(14), and for nearly century splenectomy has been an accepted practice in management of hematological diseases $(15,16,17)$. ITP is the most common and thoroughly studied and affecting more than 14,000 new patients every year in United States.

In our study 30 patients were included, while the number of patients in others studies range from 24 to 103 patients (18). N.katkhouda et al (18)study included 103 patients, Jing Wang Tin et al (19) study included 51 patients and Ahmed Nada et al (20)study included 24 patients.inspite of the fact that we intended to increase the number of patients in our study, this number is comparable with the studies mentioned above. Regarding mean splenic size, in our study was $13.3 \mathrm{~cm}$ while in N.katkhouda etal (18) study the mean splenic size was $14 \mathrm{~cm}$ and in Jing Wang Tin etal (19) was $21.6 \mathrm{~cm}$. Since our study is new and we are initiating a new technique so we started with normal size or mildly enlarged spleen, such spleens are usually found in cases of ITP that why only ITP patients were included in our study. While other studies included other indications for splenectomy in addition to ITP, like B. Thalassemia, spherocytosis and hodgkin lymphoma this explain the difference in splenic size between our study and others. The mean platelet count pre operatively in our study was $46,000 /$ ML(15 patients were have less than 50,000/ML and other 15 patients were have platelet count more than 50,000/ML) and this because we could not reach the count more than 50,000/ ML duo to the fact that we depend on steroid pre operatively while in N.katkhouda et al(18) study the mean platelet count for the patients with ITP was $66,000 / \mathrm{ML}$ because he used immunoglobulin pre operatively for his patients to increase platelet count . Regarding mean operation time in our study was $84.3 \mathrm{~min}$. While in N.katkhouda et al (18) study was $161 \mathrm{~min}$. And in Ahmed Nada et al (20) study was $115 \mathrm{~min}$. and in Sotomayor et al (21) study was $137 \mathrm{~min}$. this difference in mean operation time can be explained by the difference in method that used in laparoscopic splenectomy they used clips or staple or ligation of individual vessels and second reason that in these studies deal with splenomegaly patients which is more difficult in manipulation during laparoscopic splenectomy and looks it takes more times. The mean estimated blood loss during operation was $105 \mathrm{ml}$ in our study while in sotomyor et al (21) study the mean estimated blood loss was $202 \mathrm{ml}$ and in F.J. Berends et al (22)study was 615 and in F. Romano et al(23) study mean estimated blood loss was $100 \mathrm{ml}$ and this difference in estimated blood loss include multifactor, one of them that the studies above dealt with normal splenic size in 
addition to splenomegaly patients and as we know increase size of spleen increase risk of bleeding and second factor is technique of operation. the bleeding is either from capsule or from the splenic vessels which are more prone for injury during dissection of splenic vessels which is used in all studies mentioned above except in F.Romano et al study who used only ligasure as we did in our study. In our study we use small Pfannenstiel incision to retrieve spleen from abdominal cavity, that was the same way used by Ahmed nada et al (20) and A.N.Dalvi et al(24) . in 3 of our patients we used retrieval bag to retrieve the spleen from site of $10 \mathrm{~mm}$ port this method used by F.Romano et al (23) and N.Katkhouda et al (18) . Regarding mean hospital stay in our study was 2.3 days while in Ahmed nada et al (20) study was 4.4 days and in F.Romano et al (23) study was 2.5 days. In our study we identified spleneculi in 5 patients out of 30 patients $(16.6 \%)$, N.Katkhouda et al (18) found spleneculi in 12 patients out of 67(16.5\%) while F.Romano et al (23) the percentage of spleneculi was found in 1 patient out of 10 patients $(10 \%)$. Regarding conversion rate was zero in our study also in Ahmed nada et al (20) study while in F. Romano et al (23) study conversion occur in 1 patient out of $10(10 \%)$ due to accidental injury to the splenic vessels and in F.J.Berends et al(22) study who used staple device for division of splenic vessels conversion occur in 11(22\%) patients and in his study he explain that the cause of conversion due to position because most of conversions occur in patients who operated in supine position . Regarding post-operative morbidity occur in 7 patients $(23.3 \%$ )in our study four of those seven patients complicated with subcutaneous ecchymosis at the site of Pfannenstiel incision which were not found in any other studies and these ecchymosis mainly complicate patients with lowest platelet count pre operatively, all of those 4 patients treated conservatively,one patient complicated by left subphrenic collection in post-operative day 10 and re admited to the hospital and treated by aspiration under ultrasound guide while in Ahmed nada et al (20) study one patient which is female with spherocytosis complicated by collection in Douglas pouch which was also treated by aspiration under ultrasound guide. In F.Romano et al (23) study 1 patient out of $10(10 \%)$ complicated by splenic portal vein thrombosis and this complication also occur in one patient in our study while in Ahmed nada et al (20) have one patient who complicated by splenomesentric vein thrombosis and in all and our study patient with this complication treated by enoxaparin,while in N.Katkhouda et al (18) study another complications occurred like plural effusion and two cases complicated by post splenectomy pancreatitis and one patient complicated by port site herniation which is treated by laparoscopic reduction of hernia and all these complications not observed in our study also no wound infection complications was recorded in our study in spite of high dose of steroid was taken by our patients also no bleeding or respiratory complications was recorded and no complication due to use of the vessel sealing instrument.

\section{Conclusion:}

Laparoscopic splenectomy with use of a vessel sealing system without staple or clips in normal size and mildly enlarged spleen is safe and effective.

\section{Author's contribution:}

Study conception \& design : Dr. Aws Khidir Jassim Acquisition of data analysis : Dr.Fareed Arrak Turkey Interpretation of data, drafting of manuscript \& critical revision ; Dr.Ahmed Ali Ibraheem

\section{References:}

1. Delaitre B, Maignien B: Observation of Splenectomy by laparoscope. Presse Médicale 1991, 2263: 20.

2. Carlos D. Godinez Jr, Adrian E. Park : Spleen in : F.Charles Brunicardi, Dana K.Anderson, Timothy R. Billiar et al, (eds.) Schwartzs principle of surgery,9th ed.specific considration,Ch.34, McGrow-hills ;2010: 2382-2427.

3. Carroll BJ, Phillips EH, Semel CJ, et al: Laparoscopic splenectomy. Surg Endosc,1992,183: 6.

4.Thibault C, Mamazza J, Létourneau R, et al: Laparoscopic splenectomy: operative technique and preliminary report. $S$ urg Laparosc Endosc, 1992, 248 :2.

5. Poulin EC, Thibaul C, DesCôteaux JG, et al: Partial laparoscopic splenectomy for trauma: technique and case report. Surg Laparosc Endosc, 1995, 306: 5.

6. Seshadri PA, Poulin EC, Mamazza J, et al: Technique for laparoscopic partial splenectomy. Surg Laparosc Endosc2000,106: 10.

7. Palmer R. [Gynecological celioscopy; its possibilities and present indications]. Sem Hop 1954;30:4440-3.

8. Nezhat C, Crowgey SR, Garrison CP. Surgical treatment of endometriosis via laser laparoscopy. Fertil Steril 1986;45:77883.

9. Ming Ping Ua, Chau Su Ou, Shw Ling Chen etal: Complications and recommended practice for electrosurgery in laparoscope. AMJ Surg. 2000; 179: 67-73.

10. Harrell AG, Kercher KW, Heniford BT. Energy sources in laparoscopy. Semin Laparosc Surg 2004;11:201-9

11. Entezari K, Hoffmann P, Goris M, Peltier A, Van Velthoven $R$. A review of currently available vessel sealing systems. Minim Invasive Ther Allied Technol 2007;16:52-7.

12. Smith $R$, Pasic $R$. The role of vessel sealing technologies in laparoscopic surgery. Surg Technol Int 2008;17:208-12.

13. Nazhat C, Lowis M, King LP: Laparoscopic vessel sealing device. Journal of the society of laparoscopic surgeons. 3rd 
ed. 2012: 2-10. IVSL

14. Delaitre B, Maignien B. Splenectomy by the laparoscopic approach: report of a case. Presse Med 1992, 2263:20.

15. Glasgow RE, Mulvihill SJ.: Laparoscopic splenectomy. World J Surg 1999, 23: 8.

16. Targarona EM, Espert JJ, Cerdan G etal. Effect of spleen size on splenectomy outcome, comparison between open and laparoscopic surgery. Surg Endosc, 1999, 13 :559-562.

17. Kitano S, Yoshida T, Bandon T etal. Laparoscopic splenectomy. Ann Acad Med Singapore. 1996, 25 : 657-659.

18. Katkhouda M, Hurwitz MB, Rivera RT: Outcome and efficasy of laparoscopic splenectomy. Annals of surgery, 1998, 228(4) : 568-578.

19. Jing WT, Yajuan C, Yuchang Tetal. Stapleless laparoscopic splenectomy with individual vessel dissection. World J Surg. 2013, 37: 2300-2305. IVSL

20. Nada A, El-Samadoni, Aboulhassan M : Stapleless laparoscopic splenectomy. Annals of paediatric surgery. 2009, 5 (4) : 247-253.

21. Sotomayor-Ramirez RK. Efficacy and safety of laparoscopic splenectomy: review of 14 adult cases using the lateral approach. Bol Asoc Med. 2009, 101(2): 43-49.

22. Berends FJ, Schep N, Cuesta MA : Haematological results of laparoscopic splenectomy for patients with ITP. Surg Endosc. 2004, 18 : 766-770.

23. Romano F, Caprotti R, Franciosi C etal. Laparoscopic splenectomy using ligasure. A preliminary experience. Surg Endosc. 2002, 16 (11) : 1608- 1611.

24. Dalvi AN, Thapar PM, Deshpande AA. Laparoscopic splenectomy using conventional instruments. J Minim Access

Surg. 2005, 1(2) : 63-69. 